\title{
Distribution of genetic variance and isolation by distance in two leaf beetle species: Oreina cacaliae and Oreina speciosissima
}

\author{
STEFFI KNOLL* \& MARTINE ROWELL-RAHIER \\ Laboratoire d'ecologie animale et entomologie, Institut de Zoologie, Université de Neuchâtel, CH-2007 Neuchâtel, \\ Switzerland
}

\begin{abstract}
The distribution of genetic variance was investigated in two closely related Oreina leaf beetle species, Oreina cacaliae and Oreina speciosissima. Populations of these alpine beetles were sampled in mountainous areas of Western Europe, the total sampling area ranging from the Pyrenees to the Czech Republic. Allozyme electrophoresis of 21 (O. cacaliae) and 16 (O. speciosissima) loci revealed high genetic variability as expressed in a high percentage of polymorphic loci (only one monomorphic locus was found in each species) and high heterozygosities. No overall linkage disequilibrium was found in either species. Extensive heterozygote deficits were observed in several samples as reflected by high $F_{\mathrm{IS}}$-values and high overall inbreeding coefficients $\left(F_{\text {IT }}\right)$ of 0.349 (O. cacaliae) and 0.503 (O. speciosissima). The overall inbreeding coefficient was mainly attributable to within-population differentiation. The high heterozygote deficits are explained by a combination of inbreeding resulting in kinship groups and a sampling effect over several such kinship groups. No explanation of the observed patterns could be found in the host plant use or altitudinal location of the samples. For $O$. cacaliae, isolation by distance was found, but not for O. speciosissima. Gene flow estimates were in the range of $\mathrm{Nm}=0.8$ to 1.5 .
\end{abstract}

Keywords: allozyme electrophoresis, Chrysomelidae, genetic variability, isolation by distance, Oreina, population structure.

\section{Introduction}

Historical, ecological and demographic processes are reflected in the genetic population structure of a species. Historically, vicariance events may lead to a biogeographical splitting of a species into two isolated and independently evolving lineages. Ecologically, intrinsic habitat discontinuities in space or time can lead to effective isolation at very small scales (Roderick, 1996 and references therein). For phytophagous insects, plant patches represent such habitat discontinuities in space that have been demonstrated as being responsible for population structuring (Guttmann et al., 1989; Rank, 1992). If it changes to a new host plant species, a herbivore generally has to develop certain adaptations: to overcome plant defence mechanisms and to adapt to a different nutritional quality or to different natural enemies. Thus, different host plants (or, more generally, 'differential use of habitat') may also

*Correspondence. E-mail: knoll@cefe.cnrs-mop.fr cause divergence. Finally, demographic processes such as group size, dispersal and the mating system ultimately mould the genetic population structure of a species.

In the leaf beetle genus Oreina (Coleoptera, Chrysomelidae, Chrysomelinae) all of these factors have been proposed as being responsible for species divergence (Dobler et al., 1996). Because they are mostly alpine species, these beetles must have undergone major habitat shifts during the last glaciation. Currently they live not only in geomorphologically and climatically very diverse environments, but within this habitat they also occur in locally subdivided groups on their host plant patches. Previous work has shown that there is considerable genetic variation within and between Oreina populations (Eggenberger \& Rowell-Rahier, 1991; RowellRahier, 1992). However, the limited number of populations in these studies could not provide an explanation for the observed patterns.

In this paper, the results are presented of a macrogeographical study on the distribution of 
genetic variability of two Oreina species, Oreina cacaliae and $O$. speciosissima. The first aim of the paper was to report and compare the genetic variability of these two sympatric sister species. Secondly, an explanation of the observed patterns was sought. Therefore, correlations were looked for between the observed genetic structure and ecological characteristics of the samples. Thereby the relative importance of different host plants, different geographical locations and different climatic regimes (as suggested from the large altitudinal range of the sites of these alpine beetles) were evaluated.

\section{Materials and methods}

\section{Natural history of the beetles}

The biogeographical range of $O$. cacaliae and $O$. speciosissima extends from north-eastern Spain, through southern France and throughout the Alps, and extends into the Karpats and the Czech and Slovakian mountains (Kühnelt, 1984). Both species are recorded between $500 \mathrm{~m}$ and $3000 \mathrm{~m}$ altitude. They occur sympatrically, feeding on the same host plant patches of perennial herbs (Adenostyles spp., Senecio nemorensis-fuchsii and Petasites albus), but $O$. speciosissima has a slightly broader ecological niche (concerning host plant spectrum, geographical range and type of chemical defence). Both species are ovoviviparous and have overlapping generations. Overwintered males and gravid females occur in early spring; larvae are laid from spring until early summer directly on the host plants. Larvae develop in four larval stages to adults either in the same year, or, if they are late, overwinter as L4 in the soil.

Oreina cacaliae and $O$. speciosissima have chemical defences (Hartmann et al., 1997) and are aposematic. They show considerable colour polymorphism. Colour is still often used in the identification of subspecies or races (e.g. Kühnelt, 1984), although only the aedeagus is considered as a reliable character for species determination (Bourdonné \& Doguet, 1991). The heritability of colour polymorphism, even though documented for other leaf beetles (Vasconcellos-Neto, 1988) is unknown for any species of the genus Oreina. Within populations, individuals of both species show only minor colour variations. Sympatric species of Oreina often show the same colour morph within one population ( $\mathrm{S}$. Dobler, pers. com.; pers. obs.). As the colours are thought to be warning signals to possible predators (birds), this could be mimicry and adaptation of individuals to the local dominating colour form and, consequently, would be under strong selective control (Vasconcellos-Neto, 1988).

\section{Sampling}

Populations of the two Oreina species were sampled mainly in summer 1993, with some additional populations sampled during the summers of 1994 and 1995. The total sampling area ranged from the central Pyrenees to the Czech Republic (Table 1).

One sample always consisted of beetles randomly taken from only one host plant patch, a patch being defined by continuous plant cover. Adult beetles were picked by hand from their host plants, brought alive to the laboratory and stored in liquid nitrogen. Samples were always more than $5 \mathrm{~km}$ apart. Because host plant patches can be very large (up to $1 \mathrm{~km}^{2}$ ) and beetles very abundant (densities from 0.8 to 3 beetles $\mathrm{m}^{-2}$, S. Knoll \& M. Rowell-Rahier, unpubl. obs.), sometimes only a fraction of the patch was sampled (the sampled area rarely exceeded $100 \mathrm{~m}^{2}$ ). Earlier studies (Rowell-Rahier, 1992) have documented high $F_{\text {IS-values for both species and }}$ explained them by a Wahlund effect. Therefore the supposedly smallest possible 'random mating unit' (beetles at the same host plant patch) was sampled to avoid sampling over more than one neighbourhood. All patches sampled were clearly dominated by one host plant species (and were classified as such), even when more than one host plant species was present in the area. Each patch was located on $1: 25000$ topographical maps and this was recorded, together with host plant species and colour of the beetles as patch characteristics (Table 1).

\section{Allozyme electrophoresis}

Thoracic muscles were homogenized in $0.1 \mathrm{~m}$ TrisEDTA buffer with 2-Mercaptoethanol, $\mathrm{pH}$ 7.0. The following 16 enzyme systems were scored in standard horizontal starch gel electrophoresis $(12 \%$ Sigma starch; for methods see Hillis \& Moritz, 1990): ACOH (aconitate hydratase EC 4.2.1.3), DDH (NADH-diaphorase EC 1.8.1.4), MDHP (malate dehydrogenase EC 1.1.1.40) and GPI (glucose-6-phosphate isomerase EC 5.3.1.9) on TCA (0.001 м Tris-citrate buffer, pH 6.7); AAT (aspartate aminotransferase EC 2.6.1.1, two loci), PEP (LA) (peptidase EC 3.4.-.-, two loci), ARK (arginine kinase EC 2.7.3.3, three loci), IDH (isocitrate dehydrogenase EC 1.1.1.42, two loci) and EST (esterase, nonspecific) on TCB $(0.05 \mathrm{M}$ Tris-citrate buffer, $\mathrm{pH}$ 8.7); and FUMH (fumarate hydratase EC 
4.2.1.2), FDH (formaldehyde dehydrogenase EC 1.2.1.1), GAPDH (glyceraldehyde-3-phosphate dehydrogenase EC 1.2.1.12), G3PDH (glycerol3-phosphate dehydrogenase EC 1.1.1.8), SOD (superoxide dismutase EC 1.15.1.1, two loci), TPI (triose-phosphate isomerase $\mathrm{EC}$ 5.3.1.1) and $\mathrm{AO}$ (aldehyde oxidase EC 1.2.3.1, two loci) on EBT (0.2 м Tris-borate buffer, $\mathrm{pH} 8.6)$. For $O$. cacaliae 21 loci could be consistently scored, for $O$. speciosissima 16 loci (Table 2). Banding patterns of all reported enzyme systems followed the ones reported in the literature (Hillis \& Moritz, 1990).

\section{Statistical analyses}

Calculations of allele frequencies and tests for linkage disequilibrium and Hardy-Weinberg equilibrium were performed using GENEPOP version 2.0 (Raymond \& Rousset, 1995). Associations of genotypes between loci were tested for each population

Table 1 Locations and environmental and ecological parameters of the sampling sites: colour-type as body colour/stripe colour

\begin{tabular}{|c|c|c|c|c|c|c|}
\hline & Mountain ridge & Altitude (m) & Latitude & Longitude & Host plant & Colour-type \\
\hline \multicolumn{7}{|l|}{ Oreina cacaliae } \\
\hline Adelboden & Alps, CH & 1500 & $46^{\circ} 28.10^{\prime}$ & $7^{\circ} 32.10^{\prime}$ & Adenostyles & Blue-green/- \\
\hline Appenzell & Alps, CH & 1300 & $47^{\circ} 16.00^{\prime}$ & $9^{\circ} 27.48^{\prime}$ & Adenostyles & Blue/- \\
\hline Cascade & Vosges, F & 950 & $48^{\circ} 05.00^{\prime}$ & $7^{\circ} 05.00^{\prime}$ & Adenostyles & Green/blue \\
\hline Hirschbach & Alps, D & 1400 & $47^{\circ} 50.00^{\prime}$ & $11^{\circ} 40.00^{\prime}$ & Adenostyles & Green/blue \\
\hline Hohwald & Vosges, F & 650 & $48^{\circ} 25.00^{\prime}$ & $7^{\circ} 20.00^{\prime}$ & Adenostyles & Green/blue \\
\hline Höllental & Alps, D & 1100 & $47^{\circ} 25.00^{\prime}$ & $11^{\circ} 05.00^{\prime}$ & Petasites & Green/blue \\
\hline Kandersteg & Alps, $\mathrm{CH}$ & 1490 & $46^{\circ} 28.15^{\prime}$ & $7^{\circ} 39.20^{\prime}$ & Adenostyles & Blue-green/- \\
\hline Lieserwasen & Vosges, F & 850 & $48^{\circ} 57.00^{\prime}$ & $6^{\circ} 50.00^{\prime}$ & Senecio & Green/blue \\
\hline Madonna & Alps, I & 1825 & $46^{\circ} 13.00^{\prime}$ & $10^{\circ} 49.00^{\prime}$ & Adenostyles & Blue/- \\
\hline Safien Thalkirch & Alps, CH & 1700 & $46^{\circ} 37.50^{\prime}$ & $9^{\circ} 16.35^{\prime}$ & Adenostyles & Blue/- \\
\hline Schneekoppe & Karkonosze, $\mathrm{Cz}$ & 1200 & $50^{\circ} 35.00^{\prime}$ & $15^{\circ} 50.00^{\prime}$ & Senecio & Green/- \\
\hline Tschiertschen & Alps, CH & 1860 & $46^{\circ} 47.55^{\prime}$ & $9^{\circ} 37.00^{\prime}$ & Adenostyles & Blue/- \\
\hline Vals & Alps, CH & 1600 & $46^{\circ} 36.00^{\prime}$ & $9^{\circ} 09.10^{\prime}$ & Adenostyles & Blue/- \\
\hline Vrin & Alps, $\mathrm{CH}$ & 1450 & $46^{\circ} 40.10^{\prime}$ & $9^{\circ} 05.40^{\prime}$ & Adenostyles & Blue/- \\
\hline Zastler & Black Forest, D & 1170 & $47^{\circ} 53.30^{\prime}$ & $8^{\circ} 00.20^{\prime}$ & Petasites & Green/blue \\
\hline \multicolumn{7}{|l|}{ Oreina speciosissima } \\
\hline Altvater & Praded, $\mathrm{Cz}$ & 700 & $50^{\circ} 10.00^{\prime}$ & $17^{\circ} 20.00^{\prime}$ & Petasites & Green/blue \\
\hline Appenzell & Alps, CH & 1300 & $47^{\circ} 16.00^{\prime}$ & $9^{\circ} 27.48^{\prime}$ & Adenostyles & Green/blue \\
\hline Boubin & Bohemian forest, $\mathrm{Cz}$ & 990 & $49^{\circ} 56.00^{\prime}$ & $13^{\circ} 50.00^{\prime}$ & Senecio & Green/red \\
\hline Hirschbach & Alps, D & 1400 & $47^{\circ} 50.00^{\prime}$ & $11^{\circ} 40.00^{\prime}$ & Petasites & Green/blue \\
\hline Tschiertschen & Alps, $\mathrm{CH}$ & 1730 & $46^{\circ} 48.05^{\prime}$ & $9^{\circ} 36.50^{\prime}$ & Adenostyles & Green/blue \\
\hline Vrin & Alps, $\mathrm{CH}$ & 1450 & $46^{\circ} 40.10^{\prime}$ & $9^{\circ} 05.40^{\prime}$ & Adenostyles & Green/blue \\
\hline Zamecek & Bohemian forest, $\mathrm{Cz}$ & 750 & $50^{\circ} 60.00^{\prime}$ & $13^{\circ} 60.00^{\prime}$ & Senecio & Green/red \\
\hline Zastler & Black Forest, D & 1170 & $47^{\circ} 53.30^{\prime}$ & $8^{\circ} 00.20^{\prime}$ & Petasites & Green/blue \\
\hline
\end{tabular}


separately. To test for Hardy-Weinberg equilibrium, results of the probability test are presented, which corresponds to the exact test for Hardy-Weinberg equilibrium. Where there are more than four alleles at a locus, instead of the complete enumeration a Markov chain method was used to estimate, in 100 batches and 1000 iterations per batch, the $P$-values and standard errors (Raymond \& Rousset, 1995). For all tests a sequential Bonferroni correction for multiple comparisons was applied.

As measures of genetic variability the number of alleles per locus, percentage of loci polymorphic and the unbiased heterozygosity estimate as well as observed heterozygosity were calculated, using the program BIOSYs-1 (Swofford \& Selander, 1981).

Unbiased estimates of $F$-statistics were calculated with FSTAT (Goudet, 1995) according to the formulae given in Weir \& Cockerham (1984). Standard deviations for single-locus estimates were calculated by jackknifing over populations, and standard errors for means by jackknifing over loci.

A possible relationship was tested between, as dependent variables, the observed genotype and one morphological trait (colour) and, as possible

Table 2 Numbers of populations of Oreina fixed (frequency of the most common allele $p=1$ ) or polymorphic (frequency of the most common allele $p<0.95 ; 95 \%$ criterion) for different loci

\begin{tabular}{|c|c|c|c|c|}
\hline \multirow[b]{2}{*}{ Locus } & \multicolumn{2}{|c|}{ O. speciosissima } & \multicolumn{2}{|c|}{ O. cacaliae } \\
\hline & $p=1$ & $p<0.95$ & $p=1$ & $p<0.95$ \\
\hline Sod2 & 12 & 4 & - & - \\
\hline Aat & 2 & 14 & 1 & 19 \\
\hline Acoh & 7 & 9 & 4 & 15 \\
\hline Aol & 1 & 15 & 1 & 18 \\
\hline Ark2 & 14 & 1 & 18 & 0 \\
\hline$D d h$ & 9 & 5 & 2 & 18 \\
\hline$F d h$ & 7 & 7 & 0 & 19 \\
\hline Fumh & 6 & 10 & 11 & 5 \\
\hline Gapdh & 0 & 15 & 0 & 21 \\
\hline Gpi & 2 & 14 & 13 & 6 \\
\hline IdhI & 10 & 3 & 18 & 1 \\
\hline Idh2 & 14 & 0 & 19 & 1 \\
\hline $\operatorname{Pep}(L a) 1$ & 1 & 14 & 7 & 13 \\
\hline $\operatorname{Pep}(L a) 2$ & 5 & 10 & 1 & 20 \\
\hline Sod1 & 14 & 1 & 2 & 15 \\
\hline$T p i$ & 1 & 14 & 4 & 15 \\
\hline Ao2 & - & - & 1 & 20 \\
\hline Ark1 & - & - & 11 & 10 \\
\hline Ark3 & - & - & 10 & 7 \\
\hline Est & - & - & 1 & 20 \\
\hline G3pdh & - & - & 1 & 20 \\
\hline$M d h p$ & - & - & 0 & 20 \\
\hline
\end{tabular}

(C) The Genetical Society of Great Britain, Heredity, 81, 412-421. explanatory factors, host plant association and geographical and altitudinal isolation (nonparametric Mantel tests, e.g. Manly, 1985). The following five distance matrices were used: the genetic distance matrix (Rogers's modified genetic distance); a 'colour-type' matrix; the geographical distance matrix; the altitudinal distance matrix; and a 'host plant' matrix. For the 'colour-type' matrix, the observed colours were coded in distinct classes and the distance between samples with beetles of the same colour was coded as 0 and that between samples with beetles of different colours as 1 . In the same way, the 'host plant' matrix coded the distance between patches dominated by the same plant species with 0 , and that between patches dominated by different plant species with 1 . Latitude and longitude of the sampling sites and altitude were recorded from $1: 25000$ topographical maps and the distance matrices were calculated from these. For each patch these characteristics are given in Table 1. Mantel tests were performed with the program R (Legendre \& Vaudor, 1991). Based on 10000 permutations, $r$-values and the significance of correlations are reported.

To account for correlations between the explanatory matrices (geographical distance, altitude and host plant), partial Mantel tests were conducted following the method of Smouse et al. (1986) whenever appropriate.

Isolation by distance was further tested as described by Slatkin (1993). Nm-values as measures of gene flow were calculated by the private alleles method adjusted for sample sizes (Barton \& Slatkin, 1986) and compared to those calculated from $F_{\mathrm{ST}}$-values.

\section{Results}

\section{Allele frequencies}

These are available from the authors on request. For each species only one locus was monomorphic $(95 \%$ criterion) in all samples (Ark2 in O. cacaliae and Idh2 in O. speciosissima). All loci except Gapdh for both species and $F d h$ and Mdhp for $O$. cacaliae were also fixed in at least one sample, some samples being fixed for different alleles (Table 2). A mean of 6.1 alleles per locus was found in O. cacaliae and of 5.9 alleles per locus in $O$. speciosissima; when excluding rare alleles $(p<0.05)$ these numbers decreased to 2.2 and 2.1 , respectively.

No latitudinal, longitudinal or altitudinal cline was found for any of the alleles with an overall frequency of $p>0.10$. 


\section{Linkage disequilibrium}

1 Oreina speciosissima. After applying sequential Bonferroni procedures only one combination of loci out of 158 possible tests gave a significant $P$-value at the 5\% level, Fumh/Aat in Safien-Rainmatte.

2 Oreina cacaliae. Out of 1987 possible tests, six showed a significant deviation from random distribution of genotypes after applying sequential Bonferroni corrections: in Ferret $D d h / T p i$; in Kandersteg Acoh/Ark2; in Zastler Ddh/Tpi; and in Lieserwasen G3pdh/Gapdh, Acoh/Pep(La)2 and G3pdh/Mdhp.

\section{Hardy-Weinberg equilibrium}

1 Oreina speciosissima. With the exact test, $24.6 \%$ (31 out of 126 possible tests) were significantly different from Hardy-Weinberg expectations after applying Bonferroni correction. Overall, for $76.9 \%$ of the polymorphic loci genotypic distribution deviated from Hardy-Weinberg equilibrium. Not surprisingly, the over all loci, over all populations test showed highly significant deviation from HardyWeinberg equilibrium $\left(\chi_{176}^{2}=\infty, P<0.001\right)$.

2 Oreina cacaliae. With the exact test, $13.6 \%$ (39 out of 287) possible tests were significantly different from Hardy-Weinberg expectations after applying Bonferroni correction. Overall, for $52.4 \%$ of the polymorphic loci genotypic distribution deviated from Hardy-Weinberg equilibrium. Again, the over all loci, over all populations test showed highly significant deviation from Hardy-Weinberg equilibrium $\left(\chi_{432}^{2}=\infty, P<0.001\right)$.

\section{Genetic variability measures}

The number of alleles per locus found in single samples was the only measure of genetic variability dependent on sample size and was therefore not considered. Percentage of polymorphic loci for O. cacaliae ranged from $33.3 \%$ (Nova Pec) to $80.9 \%$ (Adelboden and Ferret), and for O. speciosissima from $31.3 \%$ (Zamecek) to $81.3 \%$ (Safien-Rainmatte). Unbiased heterozygosity values for $O$. cacaliae ranged from 0.138 (Nova $\mathrm{Pec}$ ) to 0.365 (Ochsenalp), and for O. speciosissima from 0.140 (Appenzell) to 0.370 (Safien-Rainmatte) (Table 3).

As for single alleles, no significant correlation of any measure of genetic variability with latitude, longitude or altitude could be found.

\section{F-statistics}

1 Oreina speciosissima. A wide range of $F_{\text {IS-values }}$ was observed in the different samples, ranging from
-0.072 to +0.637 (Table 3 ). The overall inbreeding coefficient was high, with a value of $F_{\text {IT }}$ of $0.503 \pm 0.056$. This was mostly attributable to the within-population component $\left(F_{\mathrm{IS}}=0.350 \pm 0.042\right)$, although there was also considerable among-population differentiation $\left(F_{\mathrm{ST}}=0.236 \pm 0.043\right)$.

Table 3 Variability measures, $F_{\mathrm{IS}}$-values and date of sampling (H.unb., unbiased estimate of heterozygosity; H.dc, observed heterozygosity; \% loci, \% loci polymorphic (95\% criterion); $F_{\mathrm{IS}}$, mean $F_{\mathrm{IS}}$-value; date of sampling: (1) before larviposition; (2) after larviposition but before emergence of the new generation adults; (3) after the emergence of the new generation adults

\begin{tabular}{|c|c|c|c|c|c|}
\hline & H.unb. & H.dc & $\%$ loci & $F_{\text {IS }}$ & Date \\
\hline \multicolumn{6}{|l|}{ Oreina cacaliae } \\
\hline Adelboden & 0.337 & 0.257 & 80.9 & 0.270 & 2 \\
\hline Albula & 0.331 & 0.224 & 66.7 & 0.368 & 2 \\
\hline Appenzell & 0.305 & 0.274 & 76.2 & 0.102 & 2 \\
\hline Cascade & 0.252 & 0.169 & 71.4 & 0.301 & 1 \\
\hline Col Aubisque & 0.222 & 0.155 & 57.1 & 0.284 & 2 \\
\hline Ferret & 0.358 & 0.283 & 80.9 & 0.164 & 1 \\
\hline Hirschbach & 0.286 & 0.203 & 76.2 & 0.348 & 1 \\
\hline Hohwald & 0.299 & 0.203 & 66.7 & 0.276 & 1 \\
\hline Höllental & 0.256 & 0.178 & 57.1 & 0.328 & 1 \\
\hline Kandersteg & 0.339 & 0.244 & 66.7 & 0.282 & 1 \\
\hline Lieserwasen & 0.278 & 0.215 & 57.1 & 0.222 & 1 \\
\hline Madonna & 0.197 & 0.124 & 52.4 & 0.377 & 3 \\
\hline Morgins & 0.345 & 0.369 & 71.4 & -0.104 & 1 \\
\hline Nova Pec & 0.138 & 0.103 & 33.3 & 0.391 & 2 \\
\hline Ochsenalp & 0.365 & 0.300 & 71.4 & 0.186 & 2 \\
\hline Safien Thalkirch & 0.291 & 0.221 & 66.7 & 0.265 & 3 \\
\hline Schneekoppe & 0.234 & 0.175 & 47.6 & 0.241 & 2 \\
\hline Tschiertsch & 0.243 & 0.198 & 57.1 & 0.206 & 2 \\
\hline Vals & 0.298 & 0.285 & 61.9 & 0.094 & 3 \\
\hline Vrin & 0.328 & 0.265 & 61.9 & 0.195 & 3 \\
\hline Zastler & 0.272 & 0.246 & 61.9 & 0.111 & 1 \\
\hline \multicolumn{6}{|l|}{ Oreina speciosissima } \\
\hline Altvater & 0.180 & 0.128 & 50.0 & 0.277 & 2 \\
\hline Appenzell & 0.140 & 0.084 & 37.5 & 0.478 & 2 \\
\hline Boubin & 0.194 & 0.174 & 62.5 & 0.049 & 2 \\
\hline Hirschbach & 0.216 & 0.085 & 68.8 & 0.637 & 1 \\
\hline Höllental & 0.175 & 0.097 & 43.8 & 0.415 & 1 \\
\hline Hörnli & 0.268 & 0.197 & 56.3 & 0.301 & 3 \\
\hline Kiental & 0.303 & 0.149 & 62.5 & 0.517 & 1 \\
\hline Kralov & 0.267 & 0.215 & 62.5 & 0.280 & 2 \\
\hline La Lecherette & 0.236 & 0.261 & 50.0 & -0.072 & 1 \\
\hline Morgins & 0.208 & 0.145 & 56.3 & 0.305 & 1 \\
\hline Nova Pec & 0.164 & 0.159 & 37.5 & 0.042 & 2 \\
\hline Safien-Rainmatte & 0.370 & 0.197 & 81.3 & 0.466 & 3 \\
\hline Tschiertschen & 0.342 & 0.183 & 62.5 & 0.487 & 2 \\
\hline Vrin & 0.161 & 0.142 & 50.0 & 0.078 & 3 \\
\hline Zamecek & 0.181 & 0.213 & 31.3 & -0.060 & 1 \\
\hline Zastler & 0.257 & 0.163 & 56.3 & 0.393 & 1 \\
\hline
\end{tabular}

(C) The Genetical Society of Great Britain, Heredity, 81, 412-421. 
2 Oreina cacaliae. Again, there was a great range of

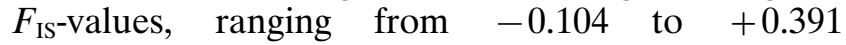
(Table 3). The overall inbreeding coefficient was somewhat lower than in O. speciosissima, $\left(F_{\text {IT }}=\right.$ $0.349 \pm 0.024)$ and, again, mostly attributable to the within-population component $\left(F_{\text {IS }}=0.229 \pm 0.029\right)$, although there was also considerable differentiation between populations $\left(F_{\mathrm{ST}}=0.155 \pm 0.028\right)$.

For both species, loci varied in their contributions to these values, some showing $F_{\mathrm{ST}}$-values not different from zero (Table 4). The high values for
Idh1 in $O$. cacaliae are caused by the single sample from the Pyrenees; removing this sample resulted in $F_{\mathrm{IT}}, F_{\mathrm{IS}}$ and $F_{\mathrm{ST}}$ for $I d h 1$ not different from zero. Idh1 is highly polymorphic in the Pyrenean sample (six alleles) and monomorphic (95\% criterion) in all other samples of $O$. cacaliae.

\section{Mantel tests}

1 Oreina speciosissima. In the pairwise Mantel tests of the five distance matrices (genetic distance,

Table $4 F$-statistics for individual loci in two Oreina species; standard errors were calculated by jackknifing over populations

\begin{tabular}{|c|c|c|c|}
\hline & $F_{\text {IS }}$ & $F_{\mathrm{ST}}$ & $F_{\text {IT }}$ \\
\hline \multicolumn{4}{|c|}{ Oreina cacaliae } \\
\hline Aat & $0.134 \pm 0.100$ & $0.355 \pm 0.104$ & $0.443 \pm 0.046$ \\
\hline Acoh & $0.246 \pm 0.093$ & $0.428 \pm 0.134$ & $0.572 \pm 0.169$ \\
\hline Aol & $0.198 \pm 0.021$ & $0.034 \pm 0.076$ & $0.225 \pm 0.073$ \\
\hline Ao2 & $0.300 \pm 0.017$ & $0.063 \pm 0.032$ & $0.344 \pm 0.035$ \\
\hline Ark2 & $0.519 \pm 0.082$ & $0.183 \pm 0.114$ & $0.608 \pm 0.130$ \\
\hline Ark3 & $0.867 \pm 0.013$ & $-0.020 \pm 0.268$ & $0.863 \pm 0.264$ \\
\hline Ark4 & $0.255 \pm 0.019$ & $0.053 \pm 0.127$ & $0.293 \pm 0.141$ \\
\hline$D d h$ & $0.100 \pm 0.072$ & $0.127 \pm 0.079$ & $0.215 \pm 0.052$ \\
\hline Est & $0.184 \pm 0.039$ & $0.149 \pm 0.064$ & $0.306 \pm 0.056$ \\
\hline$F d h$ & $0.171 \pm 0.049$ & $0.130 \pm 0.044$ & $0.278 \pm 0.036$ \\
\hline Fumh & $0.246 \pm 0.011$ & $0.030 \pm 0.174$ & $0.268 \pm 0.178$ \\
\hline G3pdh & $0.279 \pm 0.019$ & $0.071 \pm 0.064$ & $0.330 \pm 0.075$ \\
\hline Gapdh & $0.298 \pm 0.053$ & $0.167 \pm 0.058$ & $0.416 \pm 0.045$ \\
\hline$G p i$ & $0.308 \pm 0.016$ & $0.043 \pm 0.155$ & $0.337 \pm 0.163$ \\
\hline $\operatorname{Idh} 1$ & $0.313 \pm 0.648$ & $1.386 \pm 0.685$ & $1.475 \pm 0.130$ \\
\hline $\operatorname{Idh} 2$ & $0.173 \pm 0.232$ & $0.453 \pm 0.304$ & $0.587 \pm 0.096$ \\
\hline$M d h p$ & $0.181 \pm 0.022$ & $0.058 \pm 0.046$ & $0.228 \pm 0.046$ \\
\hline $\operatorname{Pep}(L a) 1$ & $0.294 \pm 0.083$ & $0.175 \pm 0.059$ & $0.418 \pm 0.046$ \\
\hline $\operatorname{Pep}(L a) 2$ & $0.342 \pm 0.060$ & $0.124 \pm 0.057$ & $0.422 \pm 0.064$ \\
\hline Sod2 & $0.238 \pm 0.054$ & $0.158 \pm 0.076$ & $0.357 \pm 0.088$ \\
\hline$T p i$ & $0.203 \pm 0.051$ & $0.117 \pm 0.070$ & $0.297 \pm 0.059$ \\
\hline \multicolumn{4}{|c|}{ Oreina speciosissima } \\
\hline Aat & $0.397 \pm 0.083$ & $0.256 \pm 0.077$ & $0.548 \pm 0.108$ \\
\hline Acoh & $0.270 \pm 0.013$ & $-0.005 \pm 0.127$ & $0.266 \pm 0.127$ \\
\hline Aol & $0.307 \pm 0.031$ & $0.133 \pm 0.097$ & $0.399 \pm 0.112$ \\
\hline Ark3 & $-0.034 \pm 0.037$ & $0.026 \pm 0.006$ & $-0.009 \pm 0.039$ \\
\hline$D d h$ & $0.672 \pm 0.119$ & $0.182 \pm 0.242$ & $0.760 \pm 0.199$ \\
\hline$F d h$ & $0.602 \pm 0.143$ & $0.665 \pm 0.098$ & $0.875 \pm 0.138$ \\
\hline Fumh & $0.720 \pm 0.125$ & $0.528 \pm 0.057$ & $0.859 \pm 0.144$ \\
\hline Gapdh & $0.336 \pm 0.056$ & $0.215 \pm 0.063$ & $0.478 \pm 0.078$ \\
\hline$G p i$ & $0.031 \pm 0.027$ & $0.091 \pm 0.092$ & $0.118 \pm 0.107$ \\
\hline $\operatorname{Idh} 1$ & $0.425 \pm 0.017$ & $0.136 \pm 0.283$ & $0.503 \pm 0.321$ \\
\hline $\operatorname{Idh} 2$ & $0.011 \pm 0.009$ & $-0.014 \pm 0.002$ & $-0.003 \pm 0.009$ \\
\hline $\operatorname{Pep}(L a) 1$ & $0.352 \pm 0.050$ & $0.114 \pm 0.087$ & $0.424 \pm 0.101$ \\
\hline $\operatorname{Pep}(L a) 2$ & $0.275 \pm 0.029$ & $0.091 \pm 0.100$ & $0.341 \pm 0.103$ \\
\hline Sod1 & $0.768 \pm 0.045$ & $0.062 \pm 0.505$ & $0.812 \pm 0.481$ \\
\hline Sod2 & $0.591 \pm 0.046$ & $0.273 \pm 0.052$ & $0.700 \pm 0.081$ \\
\hline$T p i$ & $0.366 \pm 0.091$ & $0.307 \pm 0.063$ & $0.557 \pm 0.095$ \\
\hline
\end{tabular}


Table 5 Results of the pairwise Mantel tests; significant results $(P<0.05)$ are in bold type. For details of the different distance matrices tested see text

\begin{tabular}{|c|c|c|c|c|c|c|c|c|}
\hline & \multicolumn{2}{|c|}{ Genotype } & \multicolumn{2}{|c|}{ Colour-type } & \multicolumn{2}{|c|}{ Distance $(\mathrm{km})$} & \multicolumn{2}{|c|}{ Altitude (m) } \\
\hline & $r$ & $P$ & $r$ & $P$ & $r$ & $P$ & $r$ & $P$ \\
\hline \multicolumn{9}{|l|}{ Oreina cacaliae } \\
\hline \multicolumn{9}{|l|}{ Genotype } \\
\hline Colour-type & -0.012 & 0.452 & & & & & & \\
\hline Host plant & 0.071 & 0.336 & -0.014 & 0.505 & 0.214 & 0.103 & 0.029 & 0.267 \\
\hline \multicolumn{9}{|c|}{ Oreina speciosissima } \\
\hline \multicolumn{9}{|c|}{ Genotype } \\
\hline Colour-type & 0.403 & 0.002 & & & & & & \\
\hline Distance (km) & 0.233 & 0.048 & 0.681 & 0.002 & & & & \\
\hline
\end{tabular}

colour, host plant, geographical distance and altitude) all combinations were significantly correlated, except for the relationship between genotype and host plant (Table 5). After removing the interaction of altitude and geographical distance, geographical distance was still positively correlated with colourtype $(r=0.62, P<0.002)$, but not with genetic distance $(r=0.14, P=0.142)$, and altitude was not significantly correlated with either genotype $(r=0.21, \quad P=0.131) \quad$ or colour-type $(r=0.26$, $P=0.082)$. Geographical distance was also positively related to colour-type after removing host plant effects $(r=0.62, P=0.001)$, so it can be concluded that there is a geographical component determining colour-type. However, there was still a positive host plant component on colour-type, even when geographical effects were removed $(r=0.36$, $P=0.003)$.

2 Oreina cacaliae. In the pairwise Mantel test, colour-type was positively correlated with altitude and allozyme genotype was positively correlated with geographical distance. No other combination showed positive correlations (Table 5).

\section{Isolation by distance and gene flow}

Slatkin's method (Slatkin, 1993) indicated isolation by distance for $O$. cacaliae $[\log (N m)=1.01-0.41$ $\log (\mathrm{km}), r^{2}=0.32$; significant relationship $(P<0.001$, Mantel test, 1000 permutations)], but not for $O$. speciosissima $\quad\left[\log (N m)=-0.39+0.09 \log (\mathrm{km}), \quad r^{2}=\right.$ 0.03 ; nonsignificant relationship $(P>0.1$, Mantel test, 1000 permutations)]. This is analogous to the result obtained from the Mantel test, where a posi- tive correlation between geographical distance and genetic distance could only be observed for O. cacaliae. The sample from the Pyrenees seems to be more greatly differentiated than could be explained by distance alone, because removal of this sample flattened the slope of the regression $[\log (\mathrm{Nm})=$ $\left.0.91-0.36 \log (\mathrm{km}) ; r^{2}=0.23\right]$, whereas removal of the other most distant sample from the Czech Republic did not $\left[\log (N m)=1.06-0.43 \log (\mathrm{km}), r^{2}=0.32\right]$.

$\mathrm{Nm}$-values, calculated as a measure of gene flow from the frequencies of private alleles, were very similar for both species (1.33 for O. speciosissima and 1.51 for $O$. cacaliae). $\mathrm{Nm}$-values calculated from $F_{\mathrm{ST}}$ were both smaller, 0.81 for $O$. speciosissima and 1.36 for $O$. cacaliae.

\section{Discussion}

\section{Distribution of genetic variance}

Oreina cacaliae and O. speciosissima displayed a high genetic variability. Measures of genetic variability were in the same range for both species, not supporting the hypothesis of greater genetic variability in the species with broader ecological niche. In comparison with studies of other chrysomelid species, the percentage of polymorphic loci is very high; the heterozygosity values, however, are similar to those reported in Rowell-Rahier (1992) and for other Chrysomelidae (references in Knoll et al., 1996).

Considerable genetic variation was found, both within and among populations. Moreover, the within-population component was larger in both species than the amount of genetic variation

(C) The Genetical Society of Great Britain, Heredity, 81, 412-421. 
attributable to differentiation among populations ( $F_{\text {IS-values }}$ greater than $F_{\mathrm{ST}^{-}}$-values). With a high amount of within-population variance, a significant amount of between-population differentiation is expected (Wright, 1978). The high $F_{\text {Is-values }}$ reported here correspond to those reported in an earlier study (Rowell-Rahier, 1992). On the other hand, the difference in $F_{\mathrm{ST}}$-values between the two species suggested in the previous study could not be confirmed. The much lower $F_{\mathrm{ST}}$-value $(0.051)$ for O. speciosissima formerly reported was probably an artefact, because only three samples were studied and because of the wide range of single betweenpopulation $F_{\mathrm{ST}^{-}}$-values in the present study.

The high $F_{\text {IS }}$-values in this study result from substantial heterozygote deficits in almost all populations. This is not an effect of one or two single loci, nor do all loci show a similar amount of heterozygote deficit, as would be the result of inbreeding or a Wahlund effect. A homogeneous heterozygote deficit over nine polymorphic loci was, for instance, observed in the cave-dwelling beetles of the genus Speonomus (Crouau-Roy, 1988) and was explained by inbreeding.

Three possible explanations are generally invoked to explain heterozygote deficits: the presence of null alleles, inbreeding or a Wahlund effect. The possibility of null alleles can be excluded because no missing genotypes (homozygous null alleles) were found in the gels.

Bilton (1992), in a study on the dytiscid beetle Hydroporus glabriusculus, found a similar pattern of high overall genetic variance, mainly caused by high

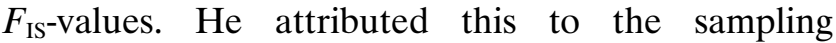
procedure conducted over several different aggregations. The sampling procedure in the study reported here was explicitly designed to avoid Wahlund effects, sampling only small and continuous host patches, within which the beetles were spaced evenly. Although the beetles do not disperse much (S. Knoll \& M. Rowell-Rahier, unpubl. obs.), a substructuring of independent groups within these patches seems unlikely.

Inbreeding should result in a homogeneous effect at all loci, which was not found here. We explain the pattern found by a combination of inbreeding resulting in kinship groups and a sampling effect over several different closely related groups.

Similar arguments have been used for the treehopper Enchenopa binotata (Guttmann et al., 1989). In this species, high differentiation among samples of nymphs on different branches of their host trees

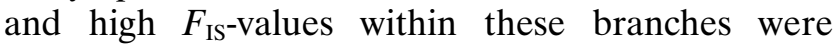
explained by sampling over the offspring of only a few females. This argument implies that later in the season (before mating) there is dispersal and thus a mixing of these sibling groups. No smaller $F_{\text {Is-values }}$ were found in the populations sampled just before larviposition, the time when most dispersal and mixing should have taken place. $F_{\text {IS }}$-values were not related to the date of sampling, so results from the present study do not represent a structuring which is not significant for the population.

The extent of inbreeding (mating with relatives) and whether this occurs by chance (because of limited dispersal) or by assortative mating can only be speculated about. There is no information about mate choice or parentship in Oreina species. In the field frequent mating can be observed up to the time of larviposition and it is known from laboratory studies that these frequent matings do not result in more larvae (S. Dobler, pers. comm.). Also, males of the previous year's generation were often observed mating with newly hatched, still soft females. Overlapping generations, in combination with low vagility, should increase the possibility and magnitude of inbreeding.

In conclusion, it is suggested that Oreina 'host plant patch' populations do not mate at random and probably constitute a mix of more or less closely related kin groups.

\section{Causes of population structuring}

A correlation of population variability with environmental parameters is an indication of local adaptation and selection (e.g. Manly, 1985). For three explanatory factors, host plant, geographical distance and altitude, tests were made for an influence on the population structure. For both species there are no host plant effects at the macrogeographical scale investigated here. This is in agreement with the results of a phylogenetic study of the genus, which documented low host fidelity and flexibility in host affiliations for the genus (Dobler et al., 1996). Autogenous defence, in combination with aposematism, is expected to promote independence from the host plant (Dobler et al., 1996). Because O. cacaliae has given up the possibility of autogenous defence, relying exclusively on sequestration of host secondary compounds, a closer association to its host as reflected in its smaller host plant spectrum would have been expected. At a microgeographical scale Kreslavsky et al. (1976) reported host races for O. cacaliae from a morphometric study based on length of elytrae. However, a morphometric study of 12 characters conducted on a subset of the populations presented here, ranked length of elytrae as not 
very informative for investigating differentiation between $O$. cacaliae or $O$. speciosissima populations. The most informative characters were those measured on the aedeagus and the length of tarsae (Gallusser, 1996).

For $O$. cacaliae, the observed population structure seems to result from isolation by distance, which, in turn, cannot be explained by selection and adaptation in geographically different areas, as indicated by the absence of any clinal pattern. Rather, the pattern of isolation by distance seems to be imposed by limited gene flow and geographical distance in an otherwise homogeneous species as originally proposed by Wright (1978). In a recent review of population structure of phytophagous insects, Peterson (1996) shows that isolation by distance is a general feature of the population structure of sedentary species on a macrogeographical scale.

The colour of $O$. cacaliae showed a strong correlation with altitude: at higher altitudes, beetles were dark blue. Melanism at high altitude is a common feature of many insect species and is commonly explained by providing better ultraviolet protection.

Colour-types are often used in chrysomelids to identify 'races' or 'subspecies' (e.g. Kühnelt, 1984 for Oreina), but so far no genetic differentiation can be shown for colour forms (Verdyck et al., 1996). Colour-type was used in the present study as a morphological character and no correlation with geographical distance was found. By contrast, in a detailed morphometric study of $O$. cacaliae (Gallusser, 1996), identical patterns were found for the morphological variation as for allozymic variation (namely 'isolation by distance' for both data sets). However, the study revealed that there is no correlation between the morphological data set and the allozyme data set, although data were obtained from the same individuals. Geographical distance is influencing both of them independently.

For O. speciosissima none of the tested environmental factors (geographical distance, altitude and host plant) was correlated with genotype. However, colour-type was correlated with geographical distance and host plant. This might reflect a flaw in the sampling regime employed in this study. The populations from the Czech Republic all belong to a specific colour-type (green with red stripes, found nowhere else), and the population from Hörnli is the only black one and the only one on Cirsium spinosissimum (Table 1). Oreina speciosissima showed no indication of isolation by distance and low $N m$-values around one, which could be interpreted as indicating a species not at equilibrium with virtually no ongoing gene flow (Slatkin, 1993).
However, the sampling for O. speciosissima populations was not as intensive as for $O$. cacaliae, and it might not have the power to detect isolation by distance (Slatkin \& Maddison, 1990; Slatkin, 1993). This seems more likely, as there is no explanation for why $O$. cacaliae should have reached an equilibrium state, whereas $O$. speciosissima has not.

\section{Conclusion}

Both species show comparable amounts of genetic variation and considerable population structuring. In $O$. cacaliae the observed structure can be explained by the isolation-by-distance model-limited gene flow in a sedentary species over larger distances-whereas for O. speciosissima no such explanation could be found. For both species, no host plant effect can be detected. Obviously, demographic processes play an important role in determining the distribution of genetic variation in Oreina species and merits further investigation.

\section{Acknow ledgements}

We would like to thank B. Benrey, S. Dobler, J. Goudet, C. Liepert, J.M. Pasteels and T. Turlings for helpful comments on an earlier draft of the manuscript. C. Knoll and G. Schwarzbözl helped with sampling in the Pyrenees and H. Kippenberg kindly indicated Oreina sites. This work was supported by the Swiss National Science Foundation (grant no. 31-33669.92).

\section{References}

BARTON, N. H. AND SLATKIN, M. 1986. A quasi-equilibrium theory of the distribution of rare alleles in a subdivided population. Heredity, 56, 409-415.

BILTON, D. T. 1992. Genetic population structure of the postglacial relict diving beetle Hydroporus glabriusculus Aubé (Coleoptera: Dytiscidae). Heredity, 69, 503-511.

Bourdonné, J.-C. AND DOGuet, s. 1991. Données sur la biosystématique des Chrysolina L.S. Ann. Soc. Ent. Fr., 27, 29-64.

CROUAU-ROY, B. 1988. Genetic structure of cave-dwelling beetles populations: significant deficiencies of heterozygotes. Heredity, 60, 321-327.

DOBLER, S., MARDULYN, P., PASTEELS, J. M. AND ROWELLRAHIER, M. 1996. Host-plant switches and the evolution of chemical defense and life history in the leaf beetle genus Oreina. Evolution, 50, 2373-2386.

EGGENBERGER, F. AND ROWELL-RAHIER, M. 1991. Chemical defence and genetic variation. Interpopulational study of Oreina gloriosa (Coleoptera: Chrysomelidae). Naturwissenschaften, 78, 317-320.

(C) The Genetical Society of Great Britain, Heredity, 81, 412-421. 
GAlluSSER, s. 1996. Etude des differences morphometrique entre populations d'Oreina cacaliae, speciosissima et elongata. Travail de diplôme, Institut de Zoologie, Université de Neuchâtel, Neuchâtel, Switzerland.

GOUdET, J. 1995. FSTAT v. 1.2. A computer program to calculate $F$-statistics. J. Hered., 86, 485-486.

GUTTMANN, S. I., Wilson, T. AND WEIGT, L. A. 1989. Microgeographic genetic variation in the Enchenopa binotata complex (Homoptera: Membracidae). Ann. Entomol. Soc. Am., 82, 225-231.

HARTMANN, T., WITTE, L., EHMKE, A., THEURING, C., ROWELL-RAHIER, M. AND PASTEELS, M.J. 1997. Selective sequestration and metabolism of plant derived alkaloids by chrysomelid leaf beetles. Phytochemistry, 45, 489-497.

HILlis, D. M. AND MORITZ, C. 1990. Molecular Systematics. Sinauer Associates, Sunderland, MA.

KNOLL, S., ROWELL-RAHIER, M., MARDULYN, P. AND PASTEELS, J. M. 1996. Spatial genetic structure of leaf beetle species with special emphasis on alpine populations. In: Jolivet, P. H. A. and Cox, M. L. (eds) Chrysomelidae Biology, vol. 1, The Classification, Phylogeny and Genetics, pp. 379-388. SPB Academic Publishing bv, Amsterdam.

KRESLAVSKY, A. G., SOLOMATIN, V. M., MIKHEEV, A. V. AND GRITZENKO, V. V. 1976. Intrapopulation ecological differentiation in a leaf beetle Chrysochloa cacaliae. Zool. Zh., 55, 1163-1171.

KüHNELT, w. M. 1984. Monographie der Blattkäfergattung Chrysochloa (Coleoptera, Chrysomelidae). Sitzungsber. Österr. Akad. Wiss. Math.-naturw. Kl., Abt. I, 193(6-10) 171-287.

LEGENdRe, P. AND VAudor, A. 1991. Le Progiciel R. Analyse Multidimensionelle, Analyse Spatiale. Departement de sciences biologiques, Université de Montréal, Canada.

MANLy, B. F. J. 1985. The Statistics of Natural Selection on Animal Populations. Chapman and Hall, London.

PETERSON, M. A. 1996. Long-distance gene flow in the sedentary butterfly, Euphilotes enoptes (Lepidoptera: Lycaenidae). Evolution, 50, 1990-1999.

RANK, N. E. 1992. A hierarchical analysis of genetic differentiation in a montane leaf beetle Chrysomela aenei- collis (Coleoptera: Chrysomelidae). Evolution, 46, 1097-1111.

RAYMOND, M. AND ROUSSET, F. 1995. GENEPOP (version 1.2): A population genetics software for exact tests and ecumenicism. J. Hered., 86, 248-249.

RODERICK, G. K. 1996. Geographic structure of insect populations: gene flow, phylogeography, and their uses. Ann. Rev. Ent., 41, 325-352.

ROWELL-RAHIER, M. 1992. Genetic structure of leaf beetle populations: microgeographic and sexual differentiation in Oreina cacaliae and O. speciosissima. Entomologia exp. appl., 65, 247-257.

SLATKIN, M. 1993. Isolation by distance in equilibrium and non-equilibrium populations. Evolution, 47, 264-279.

SLATKIN, M. AND MADDISON, W. P. 1990. Detecting isolation by distance using phylogenies of genes. Genetics, 126, 249-260.

SMOUSE, P. E., LONG, J. C. AND SOKAL, R. R. 1986. Multiple regression and correlation extensions of the Mantel test of matrix correspondence. Syst. Zool., 35, 627-632.

SWOFFORD, D. L. AND SELANDER, R. B. 1981. BIOSYS-1: A Fortran program for the comprehensive analysis of electrophoretic data in population genetics and systematics. J. Hered., 72, 281-283.

VASCONCEllos-Neto, J. 1988. Genetics of Chelymorpha cribraria, Cassidinae: colour patterns and their ecological meanings. In: Jolivet, P., Petitpierre, E. and Hsiao, T. H. (eds) Biology of the Chrysomelidae, pp. 217-232. Kluwer Academic Publishers, Drodrecht.

VERDYCK, P., DE WOLF, H., BACKELJAU, T. AND HULSELMANS, J. 1996. A genetic study of two colour forms of Phyllotreta cruciferae (Chrysomelidae: Alticinae). In: Jolivet, P. H. A. and Cox, M. L. (eds) Chrysomelidae Biology, vol. 1, The Classification, Phylogeny and Genetics, pp. 389-397. SPB Academic Publishing bv, Amsterdam.

WEIR, B. S. AND COCKERHAM, C. C. 1984. Estimating $F$-statistics for the analysis of population structure. Evolution, 43, 1349-1368.

Wright, s. 1978. Evolution and the Genetics of Populations, vol. 4, Variability Within and Among Natural Populations. University of Chicago Press, Chicago, IL. 